\title{
ANALISA PEMBEBANAN STRUKTUR ATAS JEMBATAN BETON PRATEGANG PADA JEMBATAN SULAWESI II DI BANJARMASIN MENGGUNAKAN SNI 1725:2016
}

Rohayah $^{1}$, Abdurrahman ${ }^{2}$, Eka Purnamasari ${ }^{2}$

${ }^{1}$ Mahasiswa Program Studi Teknik Sipil Fakultas Teknik Universitas Islam Kalimantan

Muhammad Arsyad Al Banjari Banjarmasin

${ }^{2}$ Dosen Program Studi Teknik Sipil Fakultas Teknik Universitas Islam Kalimantan Muhammad

Arsyad Al Banjari Banjarmasin

E-mail: rohayah.sipil@gmail.com/HP 08

\begin{abstract}
ABSTRAK
Jembatan Sulawesi I sudah saatnya untuk ditingkatkan dari segi kapasitas yang ada dan konstruksi jembatan yang masih menggunakan kayu. Karenanya dibangun jembatan baru di sisi timur dari yang sudah ada dan disebut jembatan Sulawesi II dengan panjang 63,5 m. pada saat di rencanakan dan dibangun jembatan ini di tahun 2016 masih menggunakan peraturan pembebanan jembatan RSNI 2005, seiring dengan waktu, standart tersebut perlu diperbarui sesuai dengan kondisi terkini menggunakan SNI 1725:2016.

Perhitungan analisa struktur jembatan Sulawesi II menggunakan program SAP 2000 V19. Sedangkan, perhitungan penulangan pelat lantai prategang pada Jembatan Sulawesi II ini menggunakan metode Bittner.

Berdasarkan hasil analisa struktur menggunakan program SAP 2000 yaitu momen akibat beban sendiri adalah $6421.140 \mathrm{~kg} . \mathrm{m}$, momen akibat beban mati adalah $11713.134 \mathrm{~kg} . \mathrm{m}$, momen akibat beban hidup adalah 58640.708 kg.m sedangkan analisis perhitungan penulangan pelat lantai menggunakan metode Bittner didapatkan desain yang lebih rapat jarak penulangannya dan diameter tulangan yang lebih besar yaitu arah memanjang jembatan menggunakan diameter $16 \emptyset-$ $100 \mathrm{~mm}$ dan arah melintang jembatan diambil diameter $16 \emptyset-150 \mathrm{~mm}$. Hasil analis perhitungan beton prategang didapat gaya prategang awal (F0) diperoleh sebesar $77398.224 \mathrm{~kg}$. Desain prategang menggunakan kabel sistem VSL dengan ASTM A-416 Grade 270 dan diperoleh tipe angkur E5-31 dan $\Theta$ selongsong $12.540 \mathrm{~mm}$. Dari hasil perhitungan didapatkan jumlah tendon sebanyak 5 buah dengan jumlah strand tiap tendon sebanyak 31 strand.
\end{abstract}

Kata Kunci: SNI, Pembebanan, jembatan, beton, prategang

\section{ABSTRACT}

Sulawesi Bridge I, it's time to be upgraded in terms of existing capacity and bridge construction that still uses wood. Therefore a new bridge was built on the east side of the existing one and called the Sulawesi II bridge with a length of $63.5 \mathrm{~m}$. when the bridge was planned and built in 2016 still using the 2005 RSNI bridge loading regulation, over time, the standard needs to be updated according to the current conditions using SNI 1725: 2016.

Calculation of Sulawesi II bridge structure analysis using SAP 2000 V19 program. Meanwhile, the calculation of prestressing floor plate reinforcement on the Sulawesi II Bridge uses the Bittner method.

Based on the results of structural analysis using the SAP 2000 program, the moment due to the load itself is $6421,140 \mathrm{~kg} . \mathrm{m}$, the moment due to dead load is 11713,134 kg.m, the moment due to life load is $58640.708 \mathrm{~kg} . \mathrm{m}$ while the analysis of calculation of floor plate reinforcement using Bittner method obtained a design that more tightly the reinforcement distance and larger reinforcement diameter, namely the direction of the bridge extending using a diameter of $16 \emptyset$ $100 \mathrm{~mm}$ and the transverse direction of the bridge taken diameter $1616-150 \mathrm{~mm}$. The results of the analysis of the calculation of prestressed concrete obtained the initial prestressing force (F0) was obtained at 77398,224 kg. The prestressed design uses a VSL system cable with ASTM A-416 Grade 270 and obtained types of anchor E5-31 and ong sleeve 12,540 mm. From the calculation results, the number of tendons is 5 pieces with 31 strands of strand per tendon

Keywords:

SNI, loading, bridge, concrete, prestressing 


\section{PENDAHULUAN}

Jembatan Sulawesi II terletak di Banjarmasin yang melintasi Sungai Martapura, perbatasan Kelurahan Pasar Lama, Kelurahan Antasan Kecil Barat disisi barat dan disisi timur kelurahan Antasan Kecil Timur dengan panjang jembatan 50,8 meter, sudah saatnya untuk ditingkatkan dari segi kapasitas yang ada dan konstruksi jembatan yang masih menggunakan kayu. Karenanya dibangun jembatan baru di sisi timur dari yang sudah ada dan disebut jembatan Sulawesi II dengan panjang 63,5 m. pada saat di rencanakan dan dibangun jembatan ini di tahun 2016 menggunakan peraturan pembebanan untuk jembatan RSNI 2005, seiring dengan waktu, standart tersebut perlu diperbarui sesuai dengan kondisi terkini menggunakan SNI 1725:2016. Berdasarkan kondisi tersebut perhitungan gaya prategang sangat perlu dilakukan karena dapat mencegah berkembangnya retak dengan cara mengurangi tegangan tarik di bagian tumpuan dan daerah kritis pada kondisi beban kerja, sehingga dapat meningkatkan kapasitas lentur, geser, dan torsional penampang tersebut dalam penelitian ini jembatan menggunakan pelengkung prategang pada segmen 2, dalam penelitian ini menggunakan program SAP 2000 V19 untuk analisa struktur. sehingga penulis ingin mengetahui seberapa besar perbedaan SNI yang lama dan baru dengan mengetahui besar penulangan penulangan dan gaya prategang yang terjadi pada struktur atas jembatan.

\section{Rumusan Masalah}

Dalam rangkaian skripsi ini rumusan masalahnya adalah analisis perhitungan penulangan pelat lantai jembatan Sulawesi II dan analisis perhitungan prategang pada struktur bagian atas jembatan Sulawesi II.

\section{Tujuan dan Manfaat}

Tujuan dalam penelitian skripsi ini adalah: mengetahui analisis analisis perhitungan penulangan pelat lantai jembatan Sulawesi II, mengetahui analisis analisis perhitungan prategang pada struktur bagian atas jembatan Sulawesi II sehingga menghasilkan desain penulangan pelat lantai dan jumlah tendon yang digunanakan pada beton prategang. Manfaat dalam penelitian skripsi ini dapat memberikan informasi mengenai perhitungan pembebanan menggunakan SNI 1725:2016, dan analisa prategang pada bangunan atas jembatan "Sulawesi II" di Banjarmasin.

\section{Batasan Masalah}

Adapun batasan masalah dalam penelitian skripsi ini adalah: Perhitungan beban hanya pada struktur atas jembatan "Sulawesi II di Banjarmasin", perhitungan penulangan pelat lantai menggunakan metode Bittner, perhitungan pembebanan menggunakan SAP 2000 versi 19

\section{Tinjauan Pustaka \\ Bagian-bagian Jembatan}

Suatu bangunan jembatan pada umumnya terdiri dari enam bagian pokok, yaitu terlihat pada gambar 2.1dibawah ini.

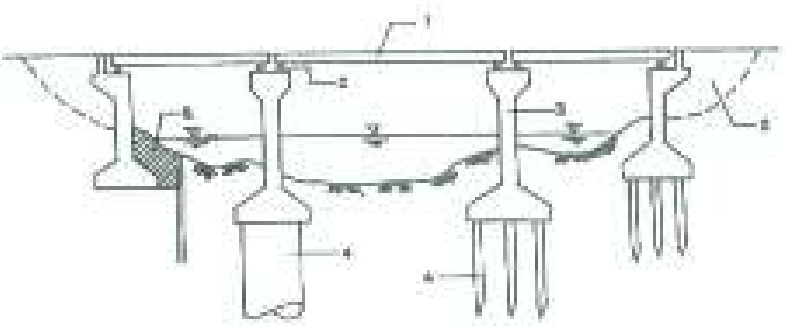

Gambar 1 Bagian-bagian Struktur Jembatan

Keterangan Gambar:

a. Bangunan atas.

b. Landasan (biasanya terletak pada pilar/abutment).

c.Bangunan bawah (berfungsi untuk memikul beban-beban bangunan atas dan pada bangunan

bawahnya sendiri untuk disalurkan pada pondasi, kemudian dari pondasi disalurkan ke tanah).

d. Pondasi.

e. Oprit (terletak dibelakang abutment, oleh karena itu tanah timbunan di belakang abutment dinuat sepadat mungkin agar tidak terjadi penurunan tanah dikemudian hari).

\section{Pembebanan Pada Jembatan}

1. Beban Mati

Beban mati terdiri dari dua jenis beban, yaitu: 
a. Berat Sendiri (Self Weight Dead)

Berat bahan dan bagian jembatan yang merupakan elemen struktural ditambah dengan elemen non structural yang dianggap tetap.

b. Beban mati tambahan (Superimposed Dead Load)

Beban Mati Tambahan adalah berat seluruh bahan, yang merupakan elemen non structural serta merupakan beban pada jembatan berupa beban aspal dan beban air hujan.

2. Beban Hidup (Live Load)

Beban hidup dalam hal ini adalah beban lalu lintas. Beban lalu lintas untuk perencanaan jembatan terdiri dari beban "D" dan beban truk "T".

a. Beban lajur "D"

Beban lajur "D" terdiri dari beban terbagi rata Uniformly Distributed Load (UDL) yang digabung dengan beban garis Knife Edge Load (KEL) seperti pada gambar 2.2

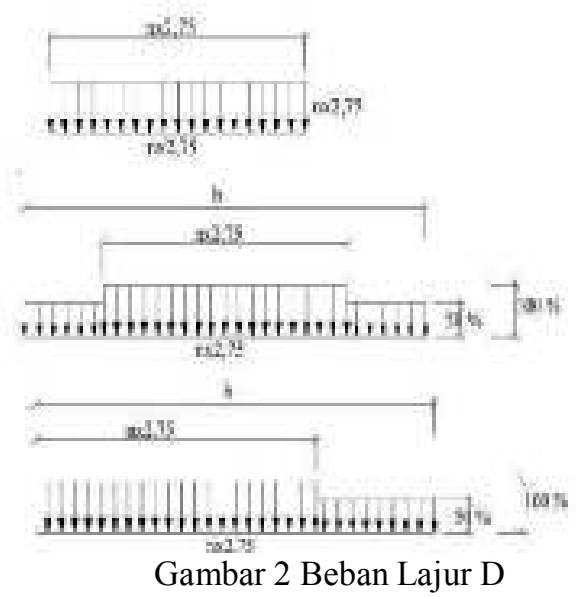

b. Pembebanan Truk "T"

Pembebanan truk "T" terdiri dari kendaraan truk semi trailer yang mempunyai susunan dan berat as seperti yang terlihat pada gambar 2.3

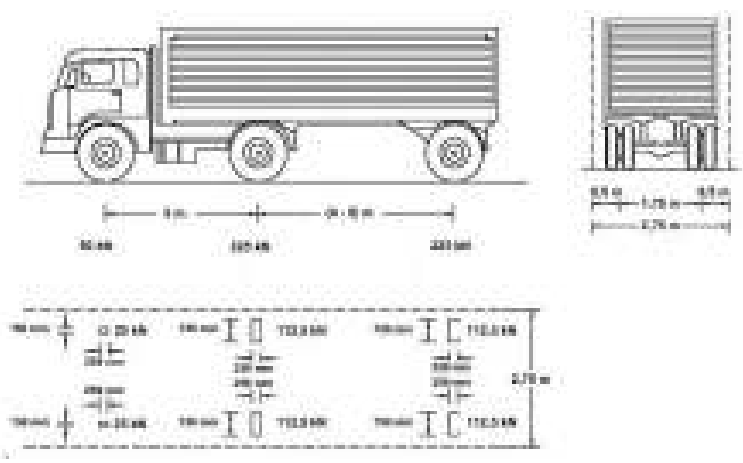

Gambar 3 Beban Truk

(sumber:SNI 1725 :2016)

c. Pembebanan untuk penjalan kaki

d. Gaya Rem

Beton Prategang

Kehilangan prategang adalah berkurangnya gaya yang bekerja pada tendon dalam tahaptahap pembebanan (Andri Budiadi, 2008 : 217). Di dalam suatu sistem struktur beton prategang selalu terdapat kehilangan gaya prategang, baik akibat sistem penegangan maupun akibat pengaruh waktu. Kehilangan tegangan langsung disebabkan oleh:

1. Perpendekan elastis dari beton.

2. Gesekan sepanjang kelengkungan tendon pada struktur pasca tarik.

3. Selip pada angkur, dll.

Kehilangan tegangan akibat pengaruh waktu disebabkan oleh:

1. Relaksasi baja, dan 
2. Perpendekan dari beton pada level baja akibat rangkak dan penyusutan

Total losses yang terjadi :

$\Delta \mathrm{f}_{\mathrm{Pt}}=\mathrm{f}_{\mathrm{Pes}}+\Delta \mathrm{f}_{\mathrm{pR}}+\Delta \mathrm{f}_{\mathrm{pCR}}+\Delta \mathrm{f}_{\mathrm{Psh}}$

$\Delta \mathrm{f}_{\mathrm{pR}}=\Delta \mathrm{fpR}\left(\mathrm{t}_{\mathrm{o}}, \mathrm{t}_{\mathrm{r}}\right)+\Delta \mathrm{f}_{\mathrm{Pr}}\left(\mathrm{t}_{\mathrm{tr}} \cdot \mathrm{t}_{\mathrm{s}}\right)$

Dengan :

$\mathrm{t}_{\mathrm{o}}=$ waktu pada saat jaxking

$\mathrm{t}_{\mathrm{tr}}=$ waktu pada saat transfer

$\mathrm{t}_{\mathrm{s}}=$ waktu pada saat losses stabil ( 5 tahun)

tegangan initial prategang dapat dihitung:

$\mathrm{f}_{\mathrm{pi}}=\mathrm{f}_{\mathrm{pJ}}-\Delta \mathrm{f}_{\mathrm{pR}}\left(\mathrm{t}_{0}, \mathrm{t}_{\mathrm{tr}}\right)-\Delta \mathrm{f}_{\mathrm{pES}}$

Losses akibat pemendekan elastic beton $\left(\mathrm{f}_{\mathrm{pES}}\right)$

Jika setelah transfer tegangan akibat $\mathrm{P}_{\mathrm{i}}$, beton mengalami pemendekan $\Delta_{\mathrm{ES}}$, maka :

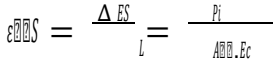

Sehingga :

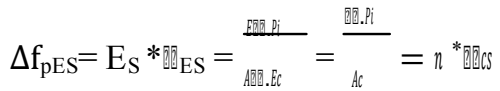

Dengan $\mathrm{f}_{\mathrm{cs}}=$ tegangan beton pada level baja akibat gaya prategang awal

\section{Program SAP 2000 V19}

SAP (Structural Analysis Program) 2000 V19 adalah program yang digunakan untuk menganalisis dan mendesain suatu struktur yang berorintasi obyek (Object Oriented Programing). Kelebihan yang sangat dominan yang dimilki oleh STAAD adalah perancangan struktur baja dan beton, dalam perancangan struktur baja SAP 2000 dapat merancang elemen-elemen struktur dengan menggunakan profil baja yang optimal dan ekonomis mungkin, sehingga dalam penggunaanya tidak perlu menentukan elemen awal dengan profil pilihan, tetapi cukup memberikan data profil dari database yang ada pada SAP 2000, ini hanya berlaku untuk perancangan struktur baja, dan sedangkan untuk perancangan struktur beton kita harus tetap menentukan elemen-elemen awal sebagai asumsional awal perancangan yang nantinya akan diperoleh luas tulangan totalnya.

\section{METODE}

Metode penelitian adalah tata cara pelaksanaan penelitian dalam rangka mencari penyelesaian atas permasalahan penelitian yang akan dilakukan. Berikut adalah bagan alir terlihat pada gambar 4 dibawah ini.

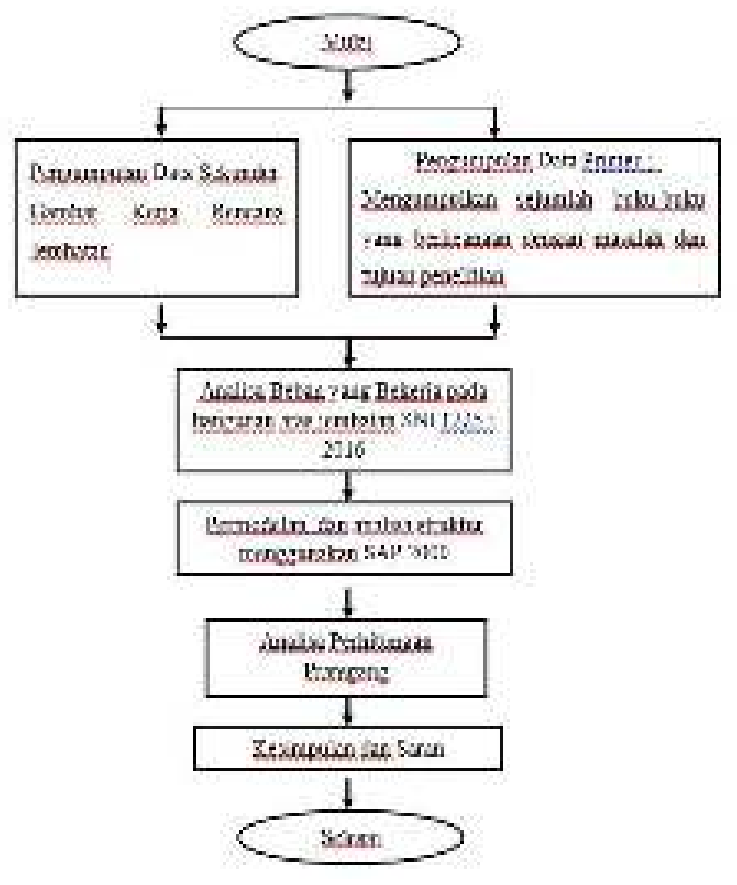

Gambar 4 Bagan alir penelitian 


\section{Data Yang Diperlukan}

Data yang diperlukan yaitu gambar kerja bangunan atas.

\section{Gambar Kerja Bangunan Atas}

Gambar detail pada bangunan jembatan Sulawesi II meliputi: jumlah gelagar beoton pelengkung pratekan, penulangan lantai pelengkung pratekan, penulangan balok

\section{Analisis Struktur Bagian Atas} V19.

Pada analisis struktur bagian atas menggunakan program aplikasi komputer yaitu SAP 2000

\section{Analisis Perhitungan Penulangan Plat Lantai}

Untuk memperoleh nilai tersebut dilakukan analisis menggunakan metode Bittner dengan menggunakan rumus-rumus yang telah dijelaskan pada bab sebelumnya.

\section{Analisis Perhitungan Prategang}

Pada analisis perhitungan prategang Untuk memperoleh nilai tersebut dilakukan analisis dengan menggunakan rumus-rumus yang telah dijelaskan pada bab sebelumnya

\section{HASIL DAN PEMBAHASAN}

\section{Hasil Perhitungan Penulangan Pelat Lantai}

Perbandingan dengan hasil perhitungan perencana sebelumnya perhitungan dengan menggunakan SNI 1725:2016 didapatkan desain yang lebih rapat jarak penulangannya dan diameter tulangan yang lebih besar. penulangan pelat lantai jembatan Sulawesi II didapatkan disimpulkan:

Arah memanjang jembatan menggunakan diameter $16 \emptyset-100 \mathrm{~mm}$

Arah melintang jembatan diambil diameter $16 \emptyset-150 \mathrm{~mm}$

\section{Hasil Perhitungan Analisis menggunakan SAP 2000 V19}

Berikut adalah tampilan Kombinasi beban hidup dan kombinasi beban mati pada program SAP 2000 V19 terlihat pada gambar 5 dibawah ini.

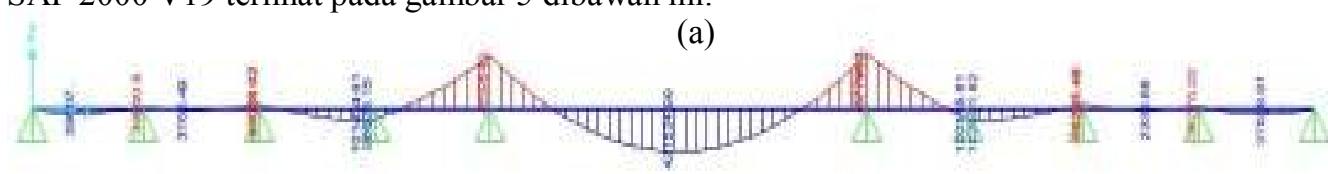

(b)

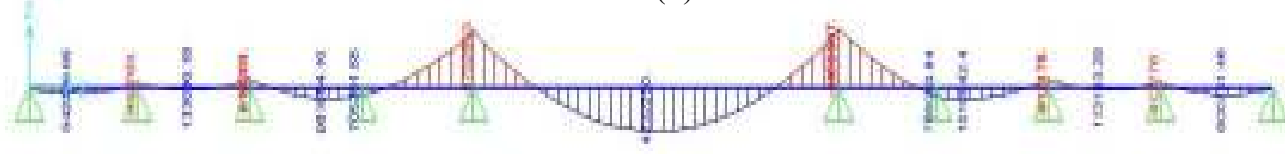

Gambar. 5(a) kombinasi beban mati (b) Kombinasi beban hidup

Berikut adalah tampilan Kombinasi beban mati pada program SAP 2000 V19 terlihat pada gambar 6 dibawah ini.

Dibawah ini adalah tampilan Diagram for frame bentang $20.6 \mathrm{~m}$ kombinasi 1 pada program SAP 2000 V19 terlihat pada gambar 6 dibawah ini.

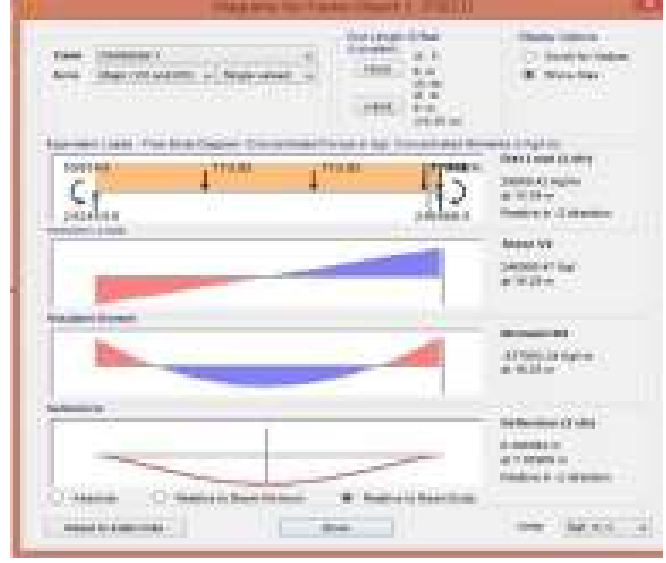


Gambar. 6 hasil diagram for frame kombinasi I

Berikut adalah tampilan hasil dari kombinasi 2 pada program SAP 2000 V19 terlihat pada gambar 7 dibawah ini.

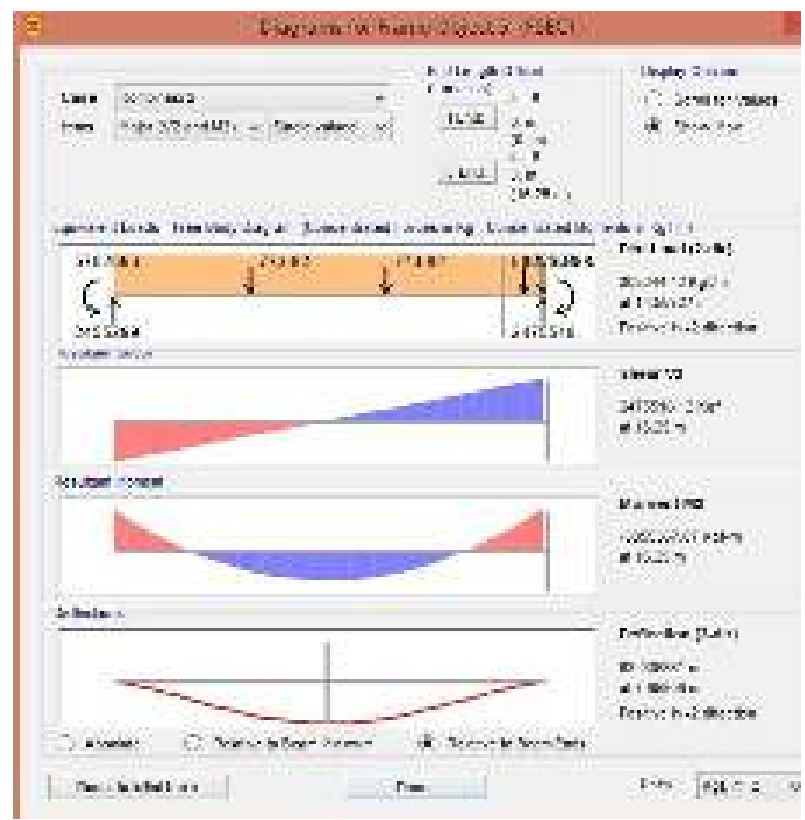

Gambar. 7 hasil diagram for frame kombinasi 2

Dari gambar di bawah ini hasil output momen menggunakan SAP 2000 V19

\begin{tabular}{|c|c|c|c|c|c|c|c|c|c|c|c|}
\hline \multicolumn{12}{|l|}{ Iase } \\
\hline ren & Solwn & Destercisen & Govins & - & $\mathrm{va}$ & $m$ & 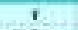 & $\omega$ & mi & crenetien & Aimencat. \\
\hline & & & tent & & $\infty$ & & & & ste & Text & is \\
\hline & $89 \times 3$ & 6 sondineit & Consuretis & 0 & 21440625 & tis & 8 & 9 & yever & 521 & axsest \\
\hline & 14545 & S. sactinual 1 & Combinatee & 0 & 20060 in & s & D & a & sesias & & Leeds \\
\hline & 7022 & teanteraes & centritive & $\mathrm{p}$ & +tesolit & , & a & $=$ & athe: & $25=$ & स०लन \\
\hline & I Merst & tentroust & conterviter & 0 & shess & s & 0 & n & Toos of & 63.1 & zxwer: \\
\hline & $1000 \mathrm{~m}$ & 6 soctruail & Contwivise & b & Leswe n? & t & 0 & : & ista: & & Lacoes \\
\hline & wath & Centerves: & Coverivats & $a$ & - Joessab & s. & a & $=$ & sarret & $i+1$ & cans \\
\hline & 1500 & Sortithent 1 & Domburmen & 。 & -15600038 & , & 0 & 8 & 1 suens 34 & 421 & nowses \\
\hline & Aine & Eonbrual t & Conbarance & 0 & alests an & t & b & $=$ & $1 \times x=4$ & & Neines \\
\hline & Aseis & zearesiant & cuetrinat & . & musesen & 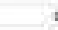 & D & $=$ & atrwes. & $s+2$ & equas \\
\hline & 28 & Scontenesit & contrinter & 0 & tesm 97 & s & 0 & I & axpes: & 13 & 9.15 \\
\hline & SE & Serrtrail 1 & Comentuse & 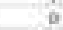 & ancass & 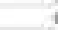 & o & 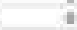 & zuns $5:$ & & 2.11 \\
\hline & Ieteit & Contruai & Comarabee & . & $\operatorname{man} 2$ & 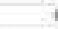 & 0 & $=$ & zoons: & 63i & soing \\
\hline & 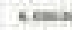 & Gevthasi: & trebrance & $B$ & sosta 4 & 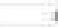 & a & $=$ & ieiria $=$ & ss-4 & crabis \\
\hline & coses: & Sentorued 1 & comprater & 0 & movan? & 1 & 0 & I & noese it? & 231 & aspers \\
\hline & теал) & Eantonai: & Compratere & o & -24060 If & 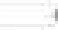 & se & : & alspre $x$ & $35-1$ & 700273 \\
\hline & xeat & teartonal & 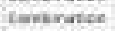 & 6 & trows $n$ & 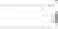 & a & , & sutis $x$ & osi & 7 covan \\
\hline & $T 95000$ & Ssontrabs! & centrvitis & o & peras & 1 & 0 & $n$ & susser & 931 & Trooxed \\
\hline & 14272 & Feanhina: & forntiranere & 0 & imenc & t & o & , & sanese & asi & casu \\
\hline & ins & comentau: & tantbritue & : & $3 x \mathrm{~m}$ & , & D & $a$ & duave : & ost & conses \\
\hline & $291 \%$ & t. conetonesis & comproven & o & $\operatorname{coses} n$ & , & D & $=$ & 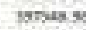 & 0.5 & s.sesea \\
\hline & sume & I earteruas: & Eombonniven & : & $\operatorname{sonas}=$ & , & 0 & : & Dowes: 5 ? & & sanss \\
\hline & we & Leantivial & cankingee & D & wenz os & $=$ & o & $=$ & Gaven & 2,4 & as \\
\hline & Dos & S. Strothue I & icombersen & 0 & $\operatorname{sen} x$ & 8 & 0 & $=$ & swosins: & 591 & 3n, \\
\hline
\end{tabular}

Gambar. 8 hasil output momen menggunakan SAP 2000 V19

\section{Perhitungan Profil Kabel}

\section{$\mathrm{F} 0=77398.224 \quad \mathrm{~kg}$}

Data kabel prategang yang digunakan adalah sebagai berikut:

Diameter $=\quad 12.540 \mathrm{~mm}$

Luas Penampang tiap strand $=$

Tegangan Tarik Batas $(\mathrm{fpu})=$

$$
98.710 \quad \mathrm{~mm} 2
$$

$1860.000 \quad$ Mpa

$=18966.792 \quad \mathrm{~kg} / \mathrm{cm} 2$

$$
\mathrm{Fpu}=18722.120 \quad \mathrm{~kg}
$$

Jumlah tendon yang diperlukan $=4.864=5 \quad$ buah tendon

Gaya prategang awal yang terjadi menjadi:
$\mathrm{F} 0=79569.01163 \quad \mathrm{~kg}$
$\mathrm{F}=63655.2093 \quad \mathrm{~kg}$

Kontrol Kehilangan Gaya

Kehilangan akibat perpendekan plastis beton (ES) (Y.T Lin dan H.Burns, 1993:103) 
Dimana:

\begin{tabular}{|c|c|c|c|}
\hline Kes & $=$ & \multicolumn{2}{|c|}{ (Pasca tarik) } \\
\hline Es & $=$ & \multicolumn{2}{|l|}{$1950000 \mathrm{~kg} / \mathrm{cm} 2$} \\
\hline MG & $=$ & 20226.591 & kg.m \\
\hline I & $=$ & 4132364.92 & $\mathrm{~cm} 4$ \\
\hline $\mathrm{e}$ & $=$ & $15 \mathrm{~cm}$ & \\
\hline F0 & $=$ & 77398.224 & $\mathrm{~kg}$ \\
\hline A & $=$ & 3500.000 & $\mathrm{~cm} 2$ \\
\hline $\mathrm{f}^{\prime} \mathrm{c}$ & $=$ & $30 \quad \mathrm{MPa}$ & \\
\hline Eci & $=$ & 81406.388 & $\mathrm{~kg} / \mathrm{cm} 2$ \\
\hline Fcir & $=$ & \multirow{2}{*}{$\begin{array}{ll}22.114+4.214 \\
18.986 \mathrm{~kg} / \mathrm{cm} 2\end{array}$} & -7.342 \\
\hline & $=$ & & \\
\hline $\mathrm{ES}$ & $=$ & $227.394 \mathrm{~kg} / \mathrm{cm} 2$ & $=18.874 \mathrm{MPa}$ \\
\hline
\end{tabular}

Kehilangan akibat pengangkuran (ANC) (Y.T Lin dan H.Burns)

Dimana:

\begin{tabular}{|c|c|c|c|c|}
\hline$\Delta \mathrm{a}$ & $=$ & $\mathrm{mm}$ & $=$ & 0.25 \\
\hline & $=$ & 20.6 & $=$ & 2060 \\
\hline $\mathrm{NC}$ & $=$ & $118.325 \mathrm{~kg} / \mathrm{cm} 2$ & $=$ & 9.821 \\
\hline
\end{tabular}

Kehilangan akibat rangkak (CR)

Dimana:

$\mathrm{Kcr}=1.6$

fcds $=7.342 \mathrm{~kg} / \mathrm{cm} 2$

$\mathrm{CR}=446.269 \mathrm{~kg} / \mathrm{cm} 2=37.040 \mathrm{MPa}$

Kehilangan akibat susut beton (SH)

$\mathrm{SH}=400.000 \mathrm{~kg} / \mathrm{cm} 2=$

Kehilangan akibat relaksasi baja (RE)

$\mathrm{RE}=548.868 \mathrm{~kg} / \mathrm{cm} 2=45.556 \mathrm{MPa}$

Kehilangan akibat gesekan (FR)

Dimana:

$\begin{array}{llllll}\mathrm{K} & = & 0.0002 & \alpha= & 0.058 & \\ \mathrm{~V} & = & 0.15 & \mathrm{fi}= & 15681.942 & \mathrm{~kg} / \mathrm{cm} 2 \\ \mathrm{Y} & = & 0.15 \mathrm{~m} & \mathrm{FR}= & 349.000 \mathrm{~kg} / \mathrm{c} & \\ \mathrm{L} & = & & & \end{array}$

Jumlah kehilangan gaya prategang total (TL)

$\mathrm{TL}=2089.856 \quad \mathrm{~kg} / \mathrm{cm} 2$

Persentase kehilangan prategang total adalah:

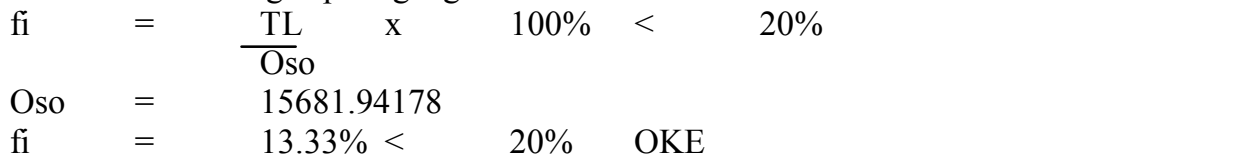

Lendutan pada saat peralihan

Akibat gaya prategang

$\Delta 1=1.526 \mathrm{~cm}=15.256 \mathrm{~mm}$

Akibat berat sendiri balok

$\begin{array}{ll}\Delta 2= & 29.996 \mathrm{~cm} \\ = & 299.963 \mathrm{~mm}\end{array} \quad \mathrm{q}=3900 \quad$ kg.m

Lendutan Total

$\Delta=\quad-28.471 \mathrm{~cm} \quad<\quad 6.867 \mathrm{~cm} \quad$ OKE

Lendutan pada saat peralihan

Akibat gaya prategang akhir

$\Delta 3=1.220 \quad \mathrm{~cm}=12.204 \mathrm{~mm}$

Akibat berat kerja

$\Delta 4=0.012 \mathrm{~cm}=0.116 \mathrm{~mm}$

Lendutan Total 


$$
\begin{aligned}
& \begin{array}{l}
\Delta=\quad-1.209 \\
\text { PENUTUP }
\end{array} \\
& \text { cm }
\end{aligned}
$$

\section{PENUTUP}

\section{Kesimpulan}

Perbandingan dengan hasil perhitungan perencana sebelumnya perhitungan dengan menggunakan SNI 1725:2016 didapatkan desain yang lebih rapat jarak penulangannya dan diameter tulangan yang lebih besar. Dari hasil perhitungan didapat gaya prategang awal (F0) diperoleh sebesar $77398.224 \mathrm{~kg}$. Desain prategang menggunakan kabel sistem VSL dengan ASTM A-416 Grade 270 dan diperoleh tipe angkur E5-31 dan $\Theta$ selongsong $12.540 \mathrm{~mm}$. Dari hasil perhitungan didapatkan jumlah tendon sebanyak 5 buah dengan jumlah strand tiap tendon sebanyak 31 strand.

\section{Saran}

Berdasarkan hasil analisis ini, beberapa saran sebagai berikut: Hasil penelitian ini masih jauh dari kesempurnaan, sehingga perlu dilakukan penelitian Untuk studi selanjutnya diharapkan agar pokok bahasan lebih luas serta meninjau analisa perhitungan bangunan bawah dan analisa perhitungan biaya agar penulisan ini dapat diaplikasikan langsung di lapangan.

\section{REFERENSI}

Badan Litbang PU Departemen Pekerjaan Umum. 2004. Standar Perencanaan Struktur Beton Untuk Jembatan (RSNI T-12-2004).

Badan Litbang PU Departemen Pekerjaan Umum. 2008. Manual Standar Perencanaan Struktur Beton Bertulang Untuk Jembatan (No.009/BM/2008).

Badan Litbang PU Departemen Pekerjaan Umum. 2016. Standar Pembebanan untuk Jembatan (SNI 1725:2016).

Purnamasari, Eka. 2010. Tugas Akhir Perencanaan Alternatif Jembatan Mantuil dengan Balok Prategang Non Prismatis. Banjarbaru. Universitas Lambung Mangkurat.

Supriyadi, Bambang dan Muntohar, Agus Setyo. 2007. Jembatan. 